\title{
Effect of Inert Diluent Segment on the Miscibility Behavior of Poly(vinylphenol) with Poly(acetoxystyrene) Blends
}

\author{
SHIAO-WEI KUO, FENG-CHIH CHANG \\ Institute of Applied Chemistry, National Chiao Tung University, Hsin Chu, Taiwan 30050, Republic of China
}

Received 17 December 2001; revised 18 February 2002; accepted 17 April 2002

\begin{abstract}
Polymer blends of poly(vinylphenol) (PVPh) and poly(styrene-co-vinylphenol) with poly(p-acetoxystyrene) (PAS) were prepared by solution casting from tetrahydrofuran solution. The thermal properties and hydrogen bonding of the blends were investigated by differential scanning calorimetry (DSC) and Fourier transform infrared spectroscopy. Although hydrogen bonding existed between the PVPh and PAS segments, the experimental results indicated that PVPh is immiscible with PAS as shown by the existence of two glass-transition temperatures over the entire composition range by DSC. This phenomenon is attributed to the strong self-association of PVPh, intramolecular screening, and functional group accessibility effects of the PVPh/PAS blend system. However, the incorporation of an inert diluent moiety such as styrene into the PVPh chain renders the modified polymer to be miscible with PAS. Copolymers containing between 16 and $51 \mathrm{~mol} \%$ vinylphenol were fully miscible with PAS according to DSC studies. These observed results were caused by the reduction of the strong self-association of PVPh and the increase of the interassociation between $\mathrm{PVPh}$ and PAS segments with the incorporation of styrene on the PVPh chain. According to the Painter-Coleman association model, the interassociation equilibrium constant of $\mathrm{PVPh} / \mathrm{PAS}$ blends was determined by a model compound and polymer blend. Good correlation between these two methods was obtained after considering the intramolecular screening and functional group accessibility effect in the polymer blend. (C) 2002 Wiley Periodicals, Inc. J Polym Sci Part B: Polym Phys 40: 1661-1672, 2002
\end{abstract}

Keywords: miscibility; hydrogen bonding; poly(vinylphenol); poly(styrene-co-vinylphenol); poly(acetoxystyrene)

\section{INTRODUCTION}

Poly(vinylphenol) (PVPh) and a number of polymers with functional groups, such as carbonyl, ether, and pyridine groups, have been reported to be miscible in the amorphous phase as a result of interassociation hydrogen bonding between the hydroxyl group of PVPh and functional groups of the second polymers. ${ }^{1-5}$ Hydrogen bonding of the self-association $\left(K_{\mathrm{B}}\right)$ and interassociation equilib-

Correspondence to: F.-C. Chang (E-mail: changfc@cc. nctu.edu.tw)

Journal of Polymer Science: Part B: Polymer Physics, Vol. 40, 1661-1672 (2002) () 2002 Wiley Periodicals, Inc. rium constants $\left(K_{\mathrm{A}}\right)$ can be obtained by Fourier transform infrared spectra as well as determine the number or fractions of functional groups that are "hydrogen bonded" or "free" according to the Painter-Coleman association model (PCAM). ${ }^{6}$ In general, the self-association equilibrium constant is determined from low molar mass molecules (model compound) diluted by an inert solvent (nonpolar group) such as cyclohexane according to the Whetsel and Lady ${ }^{7}$ methodology. Moreover, the interassociation equilibrium constant can be determined by two methods, that is, Coggeshall and Saier ${ }^{8}$ methodology using model compounds and the polymer blend using PCAM. However, these self- and interassociation equilibrium con- 
stants cannot be obtained independently from their mixtures. Fortunately, the relative magnitudes of the inter- and self-association equilibrium constants are more important that dominantly determine the contribution of the free energy of mixing rather than their individual absolute values. If the interassociation is strongly favored over self-association, then the polymer blend is expected to be miscible such as the $\operatorname{poly}(p$-vinylphenol)/poly( $N$-vinylpyrrolidone) blend system $\left(K_{\mathrm{A}} / K_{\mathrm{B}} \fallingdotseq 100\right){ }^{9,10}$ Conversely, if the selfassociation is stronger than the interassociation, then the blend tends to be immiscible or partially miscible as this $\mathrm{PVPh} / \operatorname{poly}(p$-acetoxystyrene) (PAS) blend system.

In our previous study, ${ }^{11}$ we discovered that the phenolic/PAS blend is totally miscible on the basis of a single glass-transition temperature $\left(T_{\mathrm{g}}\right)$ resulting from the formation of hydrogen bonding between the hydroxyl of the phenolic and the carbonyl of PAS. Furthermore, the interassociation equilibrium constant for the phenolic/PAS blend $\left(K_{\mathrm{A}}=64.6\right)$ is greater than the self-association equilibrium constant $\left(K_{\mathrm{B}}=52.31\right)$, implying that the tendency toward forming interhydrogen bonding of the phenolic resin and PAS dominates the self-association of the phenolic resin in the mixture. Nonetheless, in this study, we found that the $\mathrm{PVPh} / \mathrm{PAS}$ blend is immiscible as shown by the existence of two $T_{\mathrm{g}}$ 's over the entire composition range by differential scanning calorimetric (DSC) analyses. Initially, this observation seems counterintuitive because of the expected hydrogen bonding between the hydroxyl group of PVPh and the carbonyl group of PAS. However, the polymer-chain architecture is significantly different from the low molar mass molecule because of intramolecular screening and functional group accessibility ${ }^{12-17}$ caused by the chain connectivity. The intramolecular screening effect is caused by an increase in the number of contacts by the same polymer chain as a result of the self-bending back of the polymer chain, and the number of interassociation hydrogen bonds per unit volume in the polymer blend will be less relative to the model compound. Moreover, the spacing between the functional group along a polymer chain and bulky side group also significantly reduces the interassociation hydrogen bonds per unit volume because of the so-called functional-group accessibility effect. This effect is attributed to steric crowding and shielding. ${ }^{15}$

Therefore, the interassociation equilibrium constant between the polymer blend and the model compound should be different after considering the intramolecular screening, functionalgroup accessibility effects, and polymer-chain architecture. In this study, we found that the interassociation equilibrium constant of the $\mathrm{PVPh} /$ PAS blend $\left(K_{\mathrm{A}}=43.1\right)$ is smaller than the selfassociation equilibrium constant of pure $\mathrm{PVPh}$ $\left(K_{\mathrm{B}}=66.8\right)$, indicating that the pure PVPh favored intrachain hydrogen bonding by themselves. As a result, the $\mathrm{PVPh} / \mathrm{PAS}$ blend system is immiscible, showing two $T_{\mathrm{g}}$ 's as a result of relatively weaker interassociation between the hydroxyl group of PVPh and the carbonyl group of PAS. However, the corresponding interassociation equilibrium constant obtained from model compounds $\left(K_{\mathrm{A}}=134.8\right)$ is significantly higher than the self-association equilibrium constant of pure PVPh $\left(K_{\mathrm{B}}=66.8\right)$, indicating that the hydroxyl group of PVPh and the carbonyl group of PAS are able to obtain a miscible polymer blend inherently. To consider this effect, the incorporation of an inert diluent such as styrene into the PVPh chain should be able to reduce the selfassociation of pure $\mathrm{PVPh}$ and increase the intermolecular association between the hydroxyl group of PVPh and the carbonyl group of PAS. Furthermore, the standard interassociation equilibrium constant (reference molar volume $=100$ $\mathrm{cm}^{3} / \mathrm{mol}$ ) will increase with the incorporation of styrene into the PVPh chain. The purpose of this study is to determine the miscibility window of poly(styrene-co-vinylphenol) (PSOH)/PAS blends and to calculate the interassociation equilibrium constant between the hydroxyl group of PVPh and the carbonyl group of PAS.

\section{EXPERIMENTAL}

\section{Samples}

$\mathrm{PVPh}$ with a weight-average molecular weight $\left(M_{\mathrm{w}}\right)$ of 9000-10,000 was purchased from PolyScience. PAS was obtained through radical polymerization of the PAS monomer using azobisisobutyronitrile initiator (1 wt \% based on monomer) at $60{ }^{\circ} \mathrm{C}$ under a nitrogen atmosphere, and the PSOH copolymers were obtained from poly(styrene-co-acetoxystyrene) copolymers after deprotection of the acetyl group. A detailed synthesis of PAS and PSOH is described in our previous study. Here, we point out that the $\mathrm{PSOH}$ copolymer sequence is nearly random in nature because the product of the reactivity ratios is near 


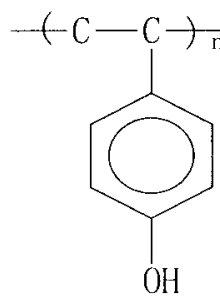

PVPh

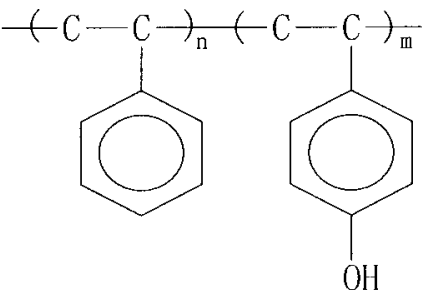

PSOH

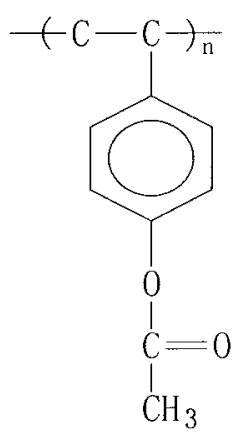

PAS

Scheme 1

$1.6\left(r_{1}=2.34, r_{2}=0.72\right)$, and monomers introduced into the polymer chain are essentially random. The chemical structures of $\mathrm{PVPh}, \mathrm{PSOH}$, and PAS are illustrated in Scheme 1.

\section{Blend Preparation}

Polymer blends of PVPh/PAS and PSOH/PAS with various compositions were prepared by solution-blending. Tetrahydrofuran (THF) solution containing 5 wt $\%$ polymer mixture was stirred for $6-8 \mathrm{~h}$, and the solution was allowed to evaporate slowly at room temperature for 1 day. The film of the blend was then dried at $50{ }^{\circ} \mathrm{C}$ for 2 days.

\section{Characterizations}

\section{DSC}

The $T_{\mathrm{g}}$ of the blend was performed using a DSC instrument from DuPont (DSC-9000) with a scan rate of $20{ }^{\circ} \mathrm{C} / \mathrm{min}$ and a temperature range of $30-180{ }^{\circ} \mathrm{C}$. The measurement was made using $5-10 \mathrm{mg}$ sample on a DSC sample cell after the sample was quickly cooled to $30^{\circ} \mathrm{C}$ from the melt of the first scan. The $T_{\mathrm{g}}$ was obtained as the inflection point of the jump heat capacity.

\section{Infrared Spectroscopy}

Infrared spectra of the polymer blend films were determined with the conventional $\mathrm{NaCl}$ dish method. The THF solution containing the blend was cast onto a $\mathrm{NaCl}$ disk and dried under condition similar to that used in the bulk preparation. The film used in this study was thin enough to obey the Beer-Lambert law. Fourier transform infrared (FTIR) measurements were recorded on a Nicolet Avatar 320 FT-IR spectrophotometer, and 32 scans were collected with a spectral resolution of $1 \mathrm{~cm}^{-1}$. For the solution sample, an adequately sealed cell with $\mathrm{NaCl}$ windows and $0.05 \mathrm{~mm}$ sample thickness was used. All model compound solutions in the absorption range obeyed the Beer-Lambert law. Cyclohexane was selected as the solvent because the specific conformation of cyclohexane is favorable in this study.

\section{RESULTS AND DISCUSSION}

\section{PVPh/PAS Blend Analyses}

DSC has been extensively used to investigate the miscibility of polymer blends. Figure 1 shows DSC thermograms for pure $\mathrm{PVPh}$, pure PAS, and various $\mathrm{PVPh} / \mathrm{PAS}$ blends. All $\mathrm{PVPh} / \mathrm{PAS}$ blends indicate two $T_{\mathrm{g}}$ 's, implying that $\mathrm{PVPh} / \mathrm{PAS}$ is an immisicible blend system, although hydrogen bonding between the hydroxyl group of PVPh and the carbonyl group of PAS is expected. This phenomenon is due to the strong self-association of the PVPh component and the relatively weaker self-association in the interassociation hydrogen bonding, revealing that the intramolecular association of the $\mathrm{PVPh}$ component is more favorable than the intermolecular interaction between the PVPh and PAS segments. Figure 2 describes the infrared spectra of the carbonyl stretching measured at $25^{\circ} \mathrm{C}$ ranging from 1680 to $1820 \mathrm{~cm}^{-1}$ for pure PAS and various PVPh/PAS blends. The carbonyl stretching frequency is split into two bands at 1760 and $1735 \mathrm{~cm}^{-1}$ corresponding to the free 


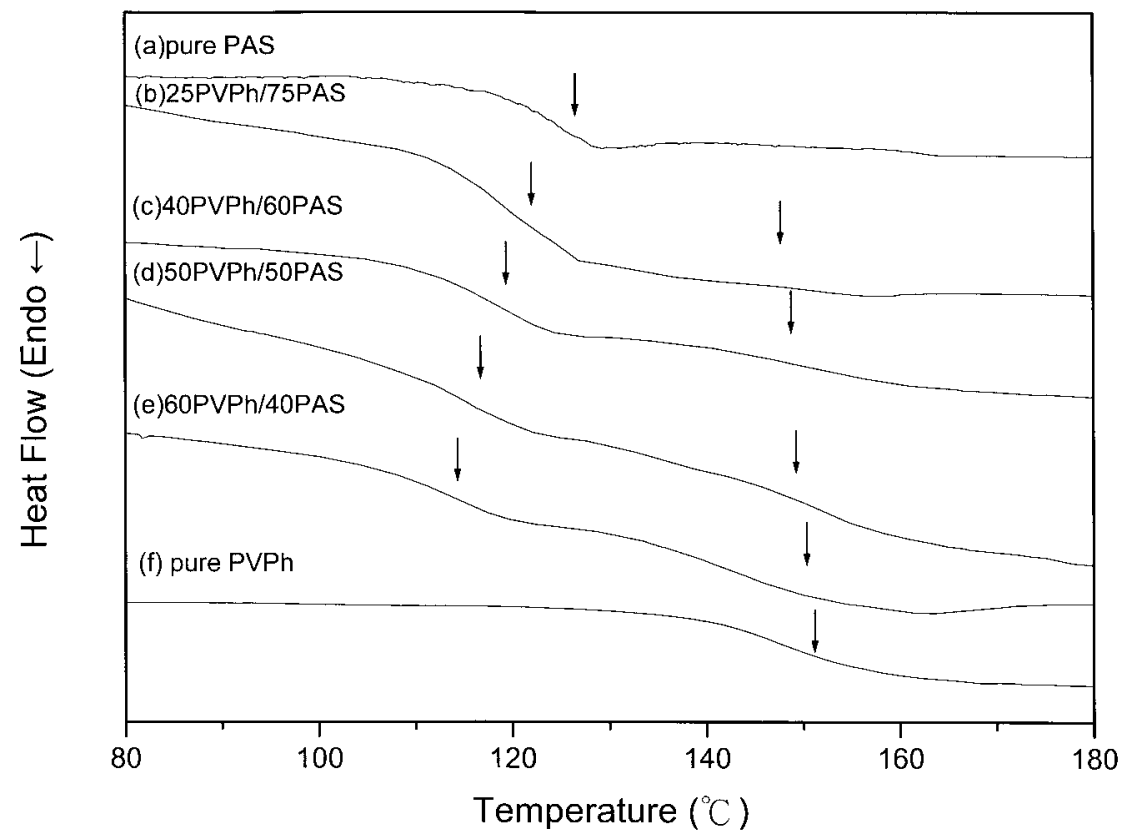

Figure 1. DSC scans of the PVPh/PAS blends with different compositions: (a) 0/100, (b) $25 / 75$, (c) 40/60, (d) 50/50, (e) 60/40, and (f) 0/100.

and hydrogen-bonded carbonyl groups, respectively. These two bands can be readily decomposed into two Gaussian peaks, with areas corresponding to the free carbonyl $\left(1760 \mathrm{~cm}^{-1}\right)$ and hydrogen-bonded carbonyl $\left(1735 \mathrm{~cm}^{-1}\right)$ absorptions. The fraction of the hydrogen-bonded carbonyl group ${ }^{6}$ is calculated from eq 1

$$
f_{\mathrm{b}}^{\mathrm{C}=\mathrm{O}}=\frac{A_{\mathrm{b}} / 1.5}{A_{\mathrm{b}} / 1.5+A_{\mathrm{f}}}
$$

where $A_{\mathrm{b}}$ and $A_{\mathrm{f}}$ are the peak areas corresponding to the hydrogen-bonded carbonyl and free carbonyl groups, respectively. The conversion coefficient of 1.5 is the absorptivity ratio of these two bands, that is, the "free" and "hydrogen bonded" carbonyl groups, in an ester group. ${ }^{6}$ Table 1 summarizes the curve-fitting results, indicating that the hydrogen-bonded fraction of the carbonyl group approaches a maximum value for the blend containing 50 wt \% PVPh [Fig. 2(d)] and then decreases gradually with an increase in the PVPh content. The observed results offer evidence that the PVPh component indeed has a stronger intramolecular association than intermolecular association because of the strong intramolecular screening effect in this blend system. As a result, the fraction of the hydrogen-bonded carbonyl group decreases with an increasing PVPh content

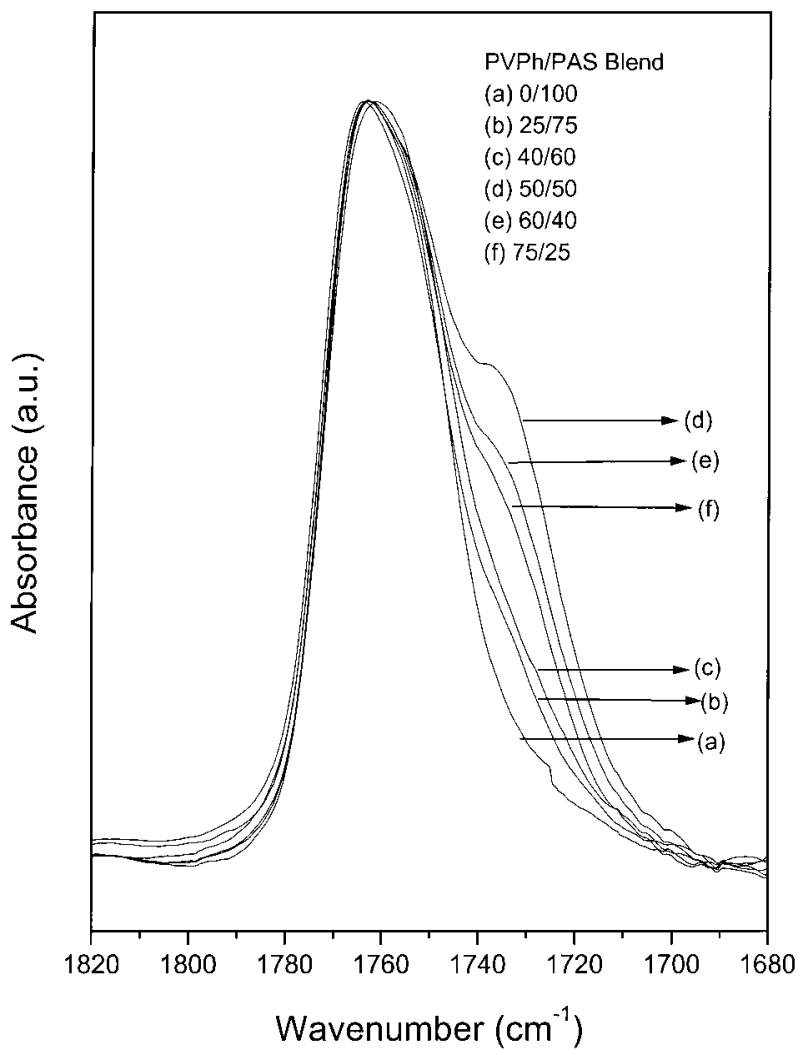

Figure 2. FTIR spectra recorded at room temperature in the $1680-1820 \mathrm{~cm}^{-1}$ region for the $\mathrm{PVPh} / \mathrm{PAS}$ blends: (a) $0 / 100$, (b) $25 / 75$, (c) 40/60, (d) 50/50, (e) $60 / 40$, and (f) $75 / 25$. 
Table 1. Curve-Fitting Result of the $\mathrm{EPh} / \mathrm{TAc}$ Blend at $25^{\circ} \mathrm{C}$

\begin{tabular}{|c|c|c|c|c|c|c|c|}
\hline \multirow{2}{*}{$\begin{array}{c}\mathrm{EPh} / \mathrm{Tac} \\
(\text { wt } \%)\end{array}$} & \multicolumn{3}{|c|}{ Free $\mathrm{C}=\mathrm{O}$} & \multicolumn{3}{|c|}{$\mathrm{H}$ Bonded $\mathrm{C}=\mathrm{O}$} & \multirow[b]{2}{*}{$f_{\mathrm{b}}^{\mathrm{a}}$} \\
\hline & $\nu\left(\mathrm{cm}^{-1}\right)$ & $A_{\mathrm{f}}(\%)$ & $\nu\left(\mathrm{cm}^{-1}\right)$ & $A_{\mathrm{b}}(\%)$ & $\nu\left(\mathrm{cm}^{-1}\right)$ & $A_{\mathrm{b}}(\%)$ & \\
\hline $25 / 25$ & 1762.2 & 63.87 & 1742.4 & 6.87 & 1730.0 & 29.25 & 36.12 \\
\hline $40 / 60$ & 1761.8 & 51.05 & 1742.9 & 8.27 & 1728.4 & 40.68 & 48.94 \\
\hline $50 / 50$ & 1761.7 & 46.79 & 1743.1 & 11.69 & 1728.3 & 41.51 & 53.20 \\
\hline $60 / 40$ & 1761.3 & 36.42 & 1743.4 & 12.50 & 1727.7 & 51.10 & 63.60 \\
\hline $75 / 25$ & 1760.5 & 30.88 & 1743.1 & 17.06 & 1727.3 & 52.04 & 69.11 \\
\hline
\end{tabular}

${ }^{\mathrm{a}} f_{\mathrm{b}}$ : fraction of hydrogen bonding.

at a higher PVPh composition. Figure 3 determines infrared spectra ranging from 2700 to 4000 $\mathrm{cm}^{-1}$ of pure $\mathrm{PVPh}$ and various $\mathrm{PVPh} / \mathrm{PAS}$ blends. The pure PVPh polymer exhibits two bands in the hydroxyl-stretching region of the infrared spectrum. A very broad band centered at $3350 \mathrm{~cm}^{-1}$ is attributed to the wide distribution of the hydrogen-bonded hydroxyl group, whereas

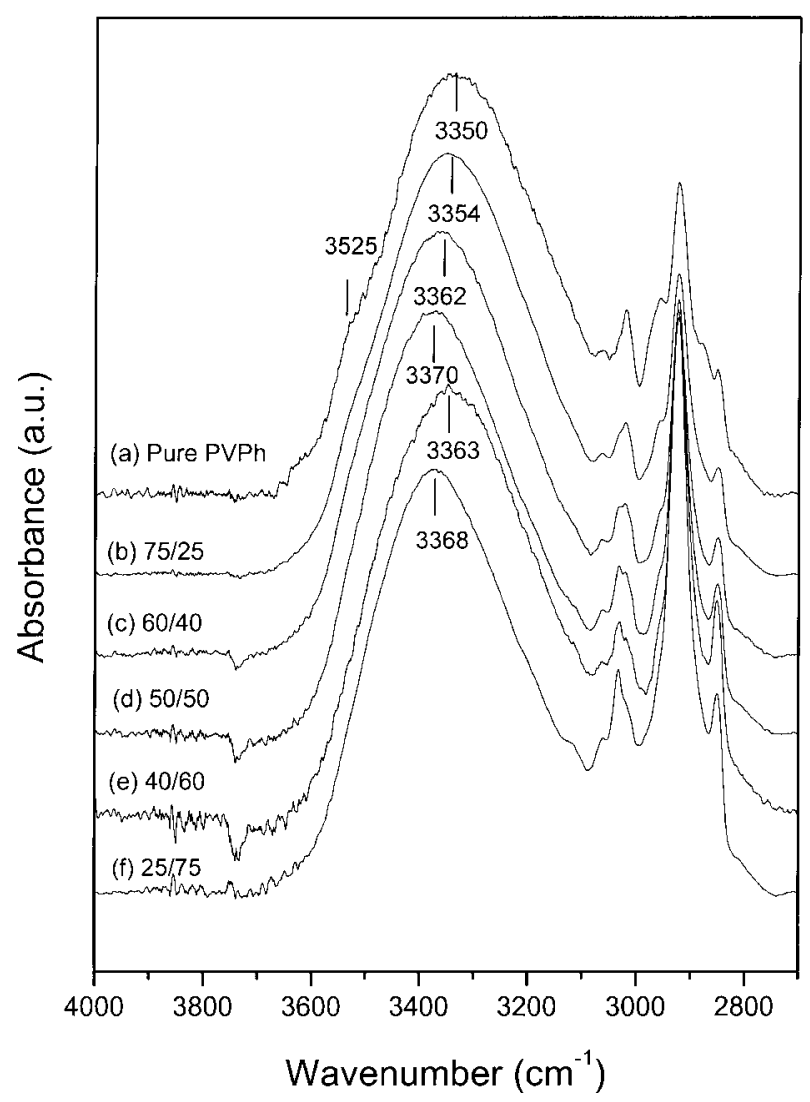

Figure 3. FTIR spectra recorded at room temperature in the $2700-4000 \mathrm{~cm}^{-1}$ region for the $\mathrm{PVPh} / \mathrm{PAS}$ blends: (a) pure PVPh, (b) 75/25, (c) 60/40, (d) 50/50, (e) $40 / 60$, and (f) $25 / 75$. the narrower band at $3525 \mathrm{~cm}^{-1}$ is from the free hydroxyl group of pure PVPh. The broad hydrogen-bonded hydroxyl band of PVPh shifts gradually into higher frequency with an increasing PAS content up to $50 \mathrm{wt} \%$ of the PAS at $3370 \mathrm{~cm}^{-1}$ [Fig. 3(d)]. This change is from the switch from the intramolecular hydroxyl-hydroxyl bond to the intermolecular hydroxyl-carbonyl bond, indicating that a hydrogen-bonding interaction exists between the PAS carbonyl group and the hydroxyl group of PVPh. Moskala et al. ${ }^{18}$ have used the frequency difference $(\Delta \nu)$ between the hydrogen-bonded hydroxyl absorption and free hydroxyl absorption to investigate the average strength of the intermolecular interaction. In this study, we found that the interassociation between hydroxyl group of PVPh and the carbonyl group of PAS is weaker than the self-association of the $\mathrm{PVPh}$ component. In addition, the PVPh component indeed possesses greater intramolecular association than intermolecular association. Furthermore, these two immiscible $T_{\mathrm{g}}$ 's shift lower relative to their homopolymers because of this phenomenon.

However, Figure 4 displays various infrared spectra of ethylphenol (EPh)/tolyl acetate (TAc) mixtures recorded at room temperature in the region from 1680 to $1820 \mathrm{~cm}^{-1}$. This free TAc carbonyl peak at $1760 \mathrm{~cm}^{-1}$ is well separated from the carbonyl group that is hydrogen bonded to the isolated $\mathrm{EPh}$ at $1740 \mathrm{~cm}^{-1}$ and multimer $\mathrm{EPh}$ at $1730 \mathrm{~cm}^{-1}$. The detailed physical picture is described in Figure 5. The corresponding area is able to decompose into three Gaussian peaks, and the curve-fitting results are summarized in Table 1, revealing that the fraction of the hydrogen-bonded carbonyl group increases with increasing $\mathrm{EPh}$ content. Certainly, the fraction of the hydrogen-bonding model compound is significantly higher than that from the polymer blend 


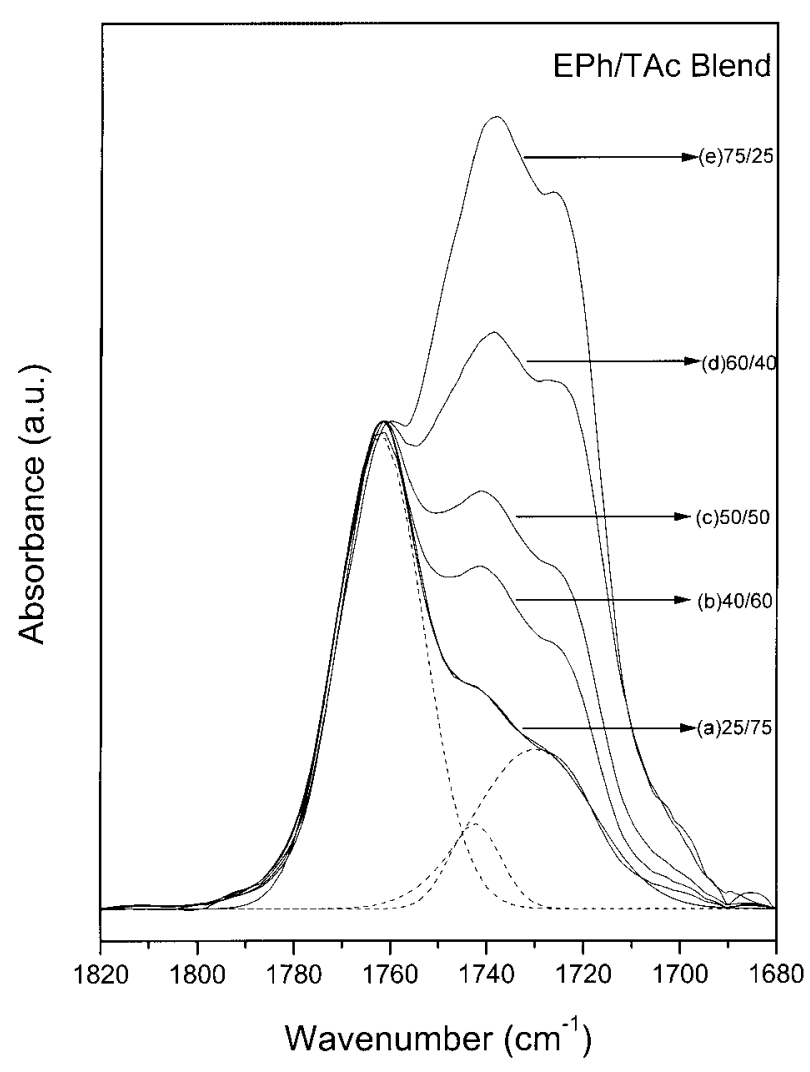

Figure 4. FTIR spectra recorded at room temperature in the $1680-1820 \mathrm{~cm}^{-1}$ region for ethylphenol/ tolyl acetate mixtures: (a) 25/50, (b) 40/60, (c) 50/50, (d) 60/40, and (e) 75/25.

because both intramolecular screening and functional-group accessibility effects are not present in the low molar mass mixture. Nonetheless, the observed result provides the clue that we can obtain a miscible blend between PVPh and PAS through modification of these two polymers. The incorporation of styrene moiety into the PVPh polymer chain can dilute and decrease the strong self-association in the $\mathrm{PVPh}$ component in the $\mathrm{PVPh} / \mathrm{PAS}$ blend. Thus, the fraction of the intermolecular hydrogen-bonding density will increase with an increasing polystyrene (PS) content in the $\mathrm{PSOH}$ copolymer.

\section{PSOH/PAS Blend Analyses}

Glass-transition behaviors of PSOH/PAS blends containing various vinylphenol contents in the $\mathrm{PSOH}$ copolymer were examined by DSC, and the results are illustrated in Figure 6. Table 3 summarizes the $T_{\mathrm{g}}$ behaviors for all $\mathrm{PSOH} / \mathrm{PAS}$ blends revealing that these copolymers containing $16-50 \mathrm{~mol} \%$ of vinylphenol are fully miscible with PAS on the basis of one $T_{\mathrm{g}}$. Figure 7 depicts the miscibility window for PSOH/PAS blends where the $x$ axis is the weight fraction of the PAS content in the blend where the $y$ axis is the molar percentage of vinylphenol in the PSOH copolymer. PAS is completely miscible with the $\mathrm{PSOH}$ copolymer containing $16-50 \mathrm{~mol} \%$ of vinylphenol.

According to the Painter-Coleman association model, two major factors are responsible for the increase in the miscibility window. First, when the difference in the solubility parameters of the two blend components is lower, the corresponding $\chi$ will also be lower. The incorporation of PS $(\delta$ $\left.=9.48 \mathrm{cal} / \mathrm{cm}^{3}\right)$ into $\mathrm{PVPh}\left(\delta=10.6 \mathrm{cal} / \mathrm{cm}^{3}\right)$ is expected to decrease its solubility parameter difference at a certain $\mathrm{PVPh}$ content with PAS $(\delta$ $=10.29 \mathrm{cal} / \mathrm{cm}^{3}$ ). Second, the relative strength of

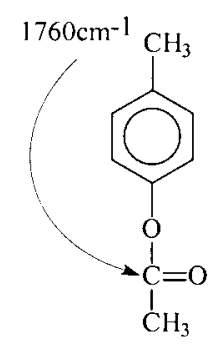

free TAc carbony!

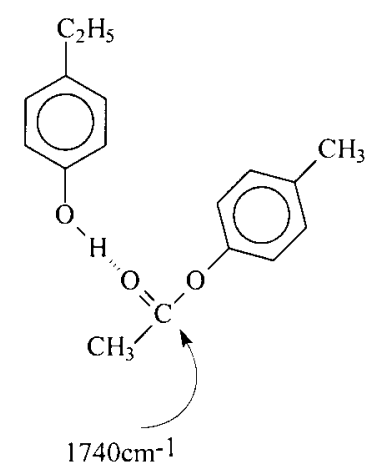

Hyrogen bonded carbonyl to isolated $\mathrm{EPh}$

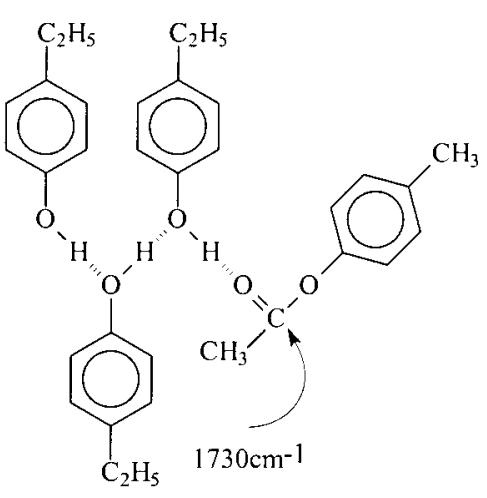

Hydrogen bonded carbonyl to multimer $\mathrm{EPh}$

Figure 5. Physical pictures of interaction between ethylphenol and tolyl acetate. 


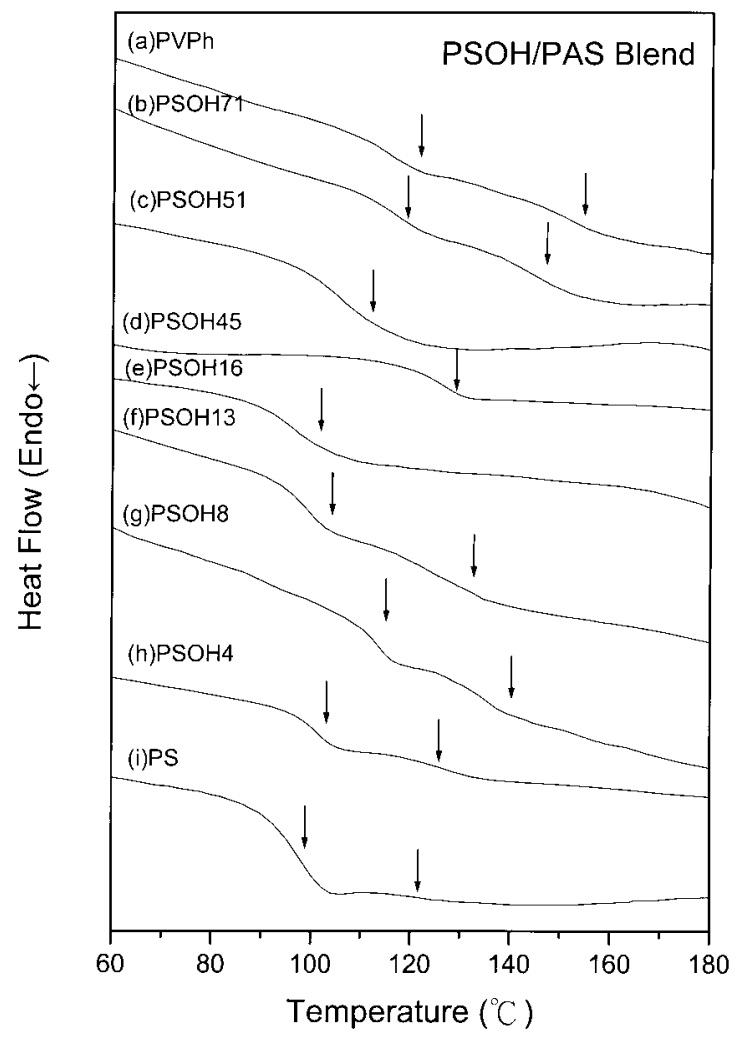

Figure 6. DSC curves of PSOH/PAS $=50 / 50$ blends containing different vinylphenol contents in $\mathrm{PSOH}$ copolymers: (a) pure PVPh, (b) PSOH71, (c) PSOH50, (d) PSOH45, (e) PSOH16, (f) PSOH13, (g) PSOH8, (h) PSOH4, and (i) pure PS.

the interassociation against the self-association $\left(K_{\mathrm{A}} / K_{\mathrm{B}}\right)$ will increase with an increase of the PS content in the PSOH copolymer and results in a more-favorable trend for miscibility. However, we need to emphasize here that the PSOH copolymer containing a lower vinylphenol content is immiscible as a result of a larger difference in the solubility parameter and a lesser total number of
Table 3. $T_{\mathrm{g}}$ Behavior of PSOH/PAS Blend by Varying Vinylphenol Content in the PSOH Copolymer

\begin{tabular}{|c|c|c|c|c|}
\hline Polymer & PAS (wt \%) & $T_{\mathrm{g}}\left({ }^{\circ} \mathrm{C}\right)$ & & \\
\hline \multirow[t]{3}{*}{$\mathrm{PVPh}$} & 25 & 123.7 & & 154.9 \\
\hline & 50 & 115.8 & & 152.4 \\
\hline & 75 & 117.2 & & 153.9 \\
\hline \multirow[t]{3}{*}{ PSOH71 } & 25 & 108.1 & & 123.1 \\
\hline & 50 & 116.1 & & 144.6 \\
\hline & 75 & 120.6 & & 145.8 \\
\hline \multirow{3}{*}{ PSOH50 } & 25 & & 116.6 & \\
\hline & 50 & & 105.8 & \\
\hline & 75 & & 105.8 & \\
\hline \multirow[t]{3}{*}{ PSOH45 } & 25 & & 126.4 & \\
\hline & 50 & & 116.9 & \\
\hline & 75 & & 122.7 & \\
\hline \multirow[t]{3}{*}{ PSOH16 } & 25 & & 124.6 & \\
\hline & 50 & & 96.7 & \\
\hline & 75 & & 125.6 & \\
\hline \multirow[t]{3}{*}{ PSOH13 } & 25 & 106.3 & & 122.6 \\
\hline & 50 & 104.5 & & 133.6 \\
\hline & 75 & 104.13 & & 122.6 \\
\hline \multirow[t]{3}{*}{ PSOH8 } & 25 & 105.5 & & 121.2 \\
\hline & 50 & 100.0 & & 133.5 \\
\hline & 75 & 95.8 & & 116.9 \\
\hline \multirow[t]{3}{*}{ PSOH4 } & 25 & 106.5 & & 122.9 \\
\hline & 50 & 101.3 & & 127.4 \\
\hline & 75 & 105.2 & & 124.7 \\
\hline \multirow[t]{3}{*}{ PS } & 25 & 97.7 & & 123.5 \\
\hline & 50 & 97.7 & & 123.0 \\
\hline & 75 & 98.6 & & 124.2 \\
\hline
\end{tabular}

hydrogen bonds of the blend. Therefore, the PSOH/PAS blend system reveals a miscibility window between 16 and $50 \mathrm{~mol} \%$ in the $\mathrm{PSOH}$ copolymer. Interestingly, Figure 8 displays the infrared spectra measured at $25{ }^{\circ} \mathrm{C}$ ranging from 1680 to $1820 \mathrm{~cm}^{-1}$ for various PSOH/PAS $=75 / 25$ blends containing different vinylphenol contents

Table 2. Curve-Fitting Result of the PVPh/PAS Blend at $25^{\circ} \mathrm{C}$

\begin{tabular}{|c|c|c|c|c|c|c|c|}
\hline \multirow{2}{*}{$\begin{array}{c}\mathrm{PVPh} / \mathrm{PAS} \\
(\mathrm{wt} \%)\end{array}$} & \multicolumn{3}{|c|}{ Free $\mathrm{C}=\mathrm{O}$} & \multicolumn{3}{|c|}{$\mathrm{H}$ Bonded $\mathrm{C}=\mathrm{O}$} & \multirow[b]{2}{*}{$f_{\mathrm{b}}^{\mathrm{a}}$} \\
\hline & $\nu\left(\mathrm{cm}^{-1}\right)$ & $\mathrm{W}_{1 / 2}\left(\mathrm{~cm}^{-1}\right)$ & $A_{\mathrm{f}}(\%)$ & $\nu\left(\mathrm{cm}^{-1}\right)$ & $W_{1 / 2}\left(\mathrm{~cm}^{-1}\right)$ & $A_{\mathrm{b}}(\%)$ & \\
\hline $25 / 25$ & 1763.7 & 18.37 & 79.51 & 1746.7 & 30.25 & 20.49 & 14.66 \\
\hline $40 / 60$ & 1762.2 & 18.82 & 69.07 & 1744.4 & 31.46 & 30.93 & 22.99 \\
\hline $50 / 50$ & 1763.6 & 17.10 & 51.94 & 1740.7 & 30.95 & 48.06 & 38.15 \\
\hline $60 / 40$ & 1763.5 & 16.92 & 57.05 & 1743.0 & 32.21 & 42.95 & 33.41 \\
\hline $75 / 25$ & 1763.8 & 17.49 & 68.90 & 1743.9 & 30.74 & 31.10 & 23.13 \\
\hline
\end{tabular}

${ }^{\mathrm{a}} \mathrm{f}_{\mathrm{b}}$ : fraction of hydrogen bonding. 


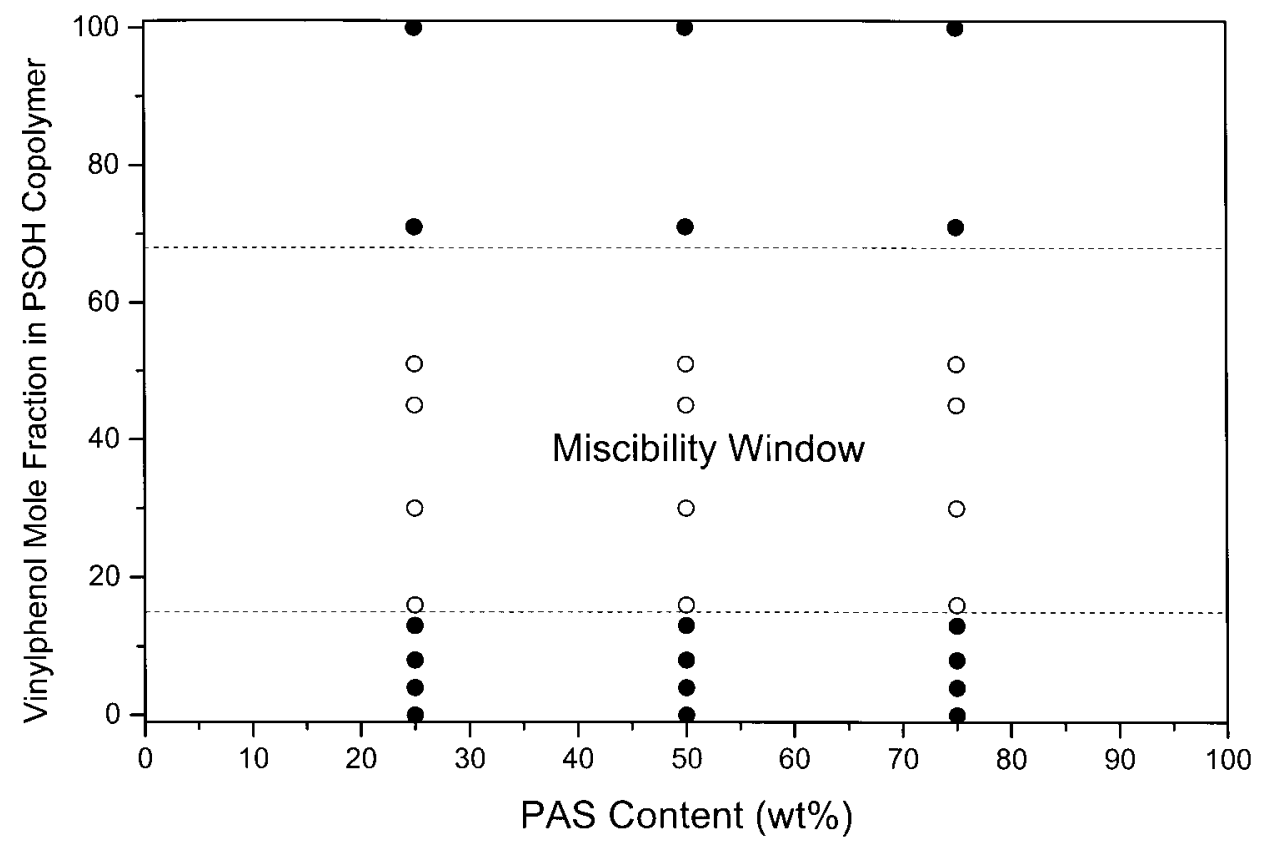

Figure 7. Miscibility window of PSOH/PAS blends.

in the PSOH copolymers. The fraction of the hydrogen-bonded carbonyl group is in the order of PSOH50 > pure PVPh > PSOH71 > PSOH8, revealing that $\mathrm{PSOH} 50 / \mathrm{PAS}=75 / 25$ has the greatest intermolecular interaction between the hydroxyl group of PVPh and the PAS carbonyl group, and this result is consistent with previous miscibility windows.

\section{Estimation of Interassociation Equilibrium Constant $\left(K_{\mathrm{A}}\right)$}

According to PCAM, the interassociation equilibrium constant $K_{\mathrm{A}}$ can be calculated by two methods. The first method was reported by Coggesthall and Saier ${ }^{8}$ involving the calculation of the hydrogen-bonding association constant, $K a$ (in $\mathrm{Lmol}^{-1}$ ), that can be expressed by the following equation:

$$
K a=\frac{1-f_{\mathrm{m}}^{\mathrm{OH}}}{f_{\mathrm{m}}^{\mathrm{OH}}\left[C_{\mathrm{A}}-\left(1-f_{\mathrm{m}}^{\mathrm{OH}}\right) C_{\mathrm{B}}\right]}
$$

where $C_{\mathrm{A}}$ and $C_{\mathrm{B}}$ denote the concentrations of $\mathrm{TAc}$ and $\mathrm{EPh}$ in moles per liter, whereas $f_{\mathrm{m}}^{\mathrm{OH}}$ represents the fraction of the free hydroxyl group of $\mathrm{EPh}$ that is defined as follows

$$
f_{\mathrm{m}}^{\mathrm{OH}}=\frac{I}{I_{0}}
$$

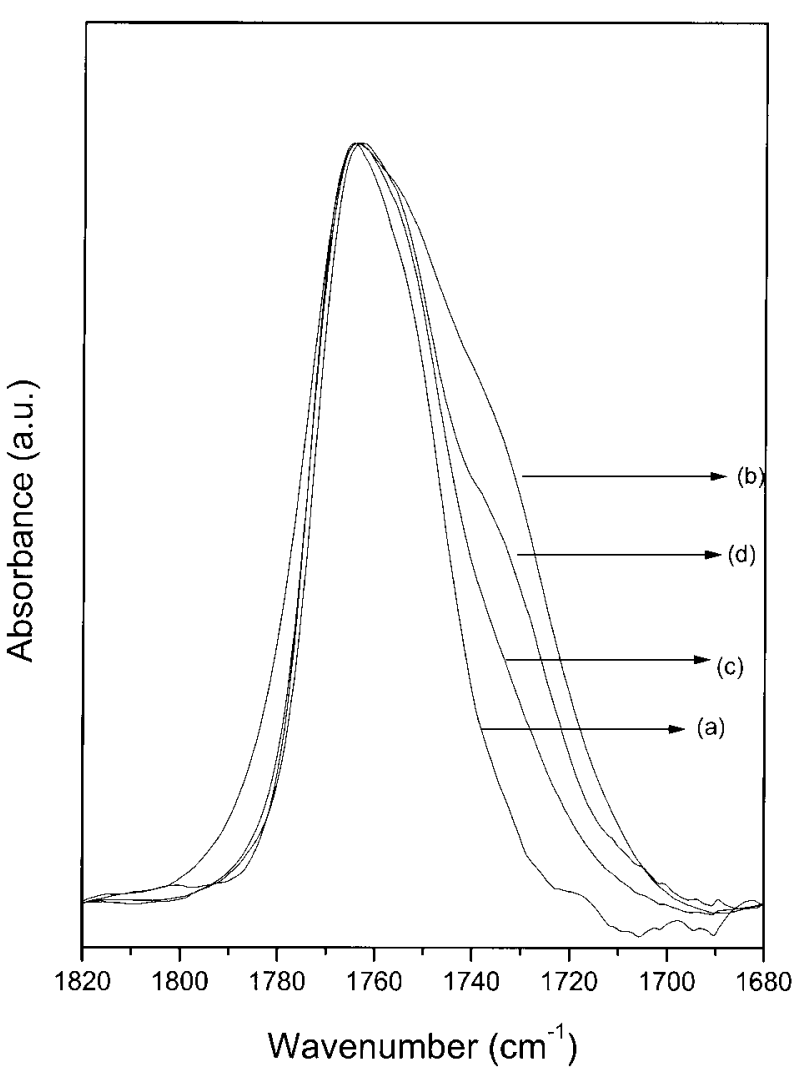

Figure 8. IR spectra at $1680-1780 \mathrm{~cm}^{-1}$ of PSOH/ PAS $=75 / 25$ blends containing different vinylphenol contents: (a) PSOH8, (b) PSOH50, (c) PSOH71, and (d) pure $\mathrm{PVPh}$. 


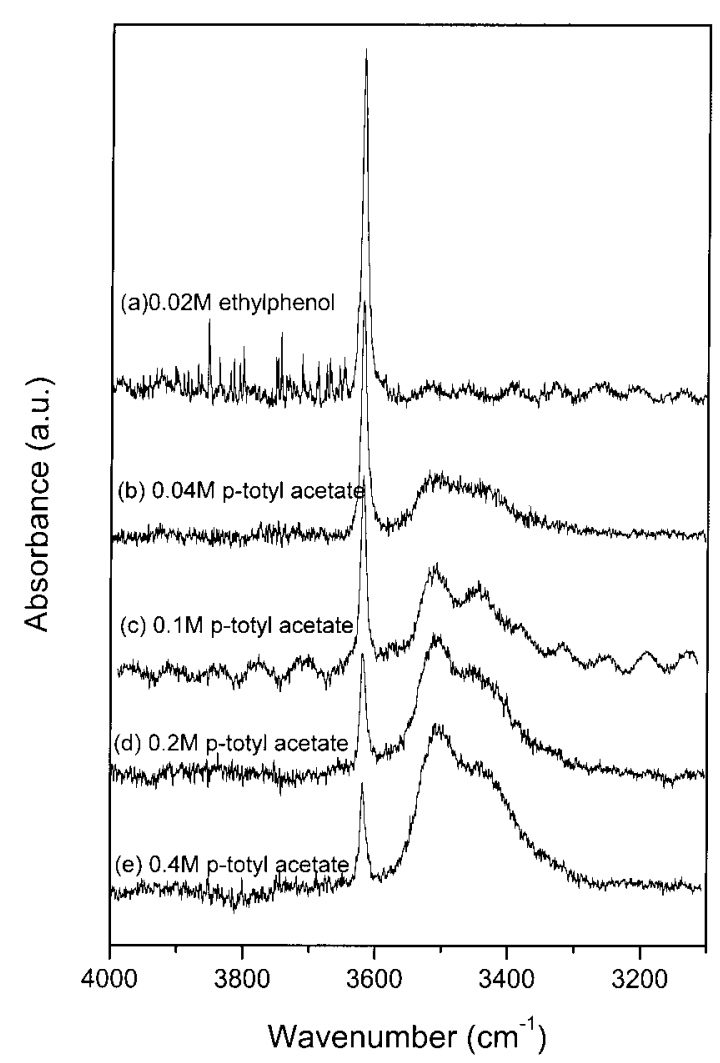

Figure 9. FTIR spectra of the hydroxyl stretching region of $0.02 \mathrm{M}$ ethylphenol containing various $p$-tolyl acetate concentrations: (a) $0 \mathrm{M}$, (b) $0.04 \mathrm{M}$, (c) $0.1 \mathrm{M}$, (d) $0.2 \mathrm{M}$, and (e) $0.4 \mathrm{M}$.

where $I_{0}=a_{F}^{O H} \cdot b \cdot c, I$ is the intensity of the free hydroxyl band, $a_{\mathrm{F}}^{\mathrm{OH}}$ is related to the absorptivity coefficient of 34.2 for $\mathrm{EPh}$ obtained previously by Hu et al., ${ }^{19} b$ is the path length $(0.05 \mathrm{~mm})$, and $c$ is the concentration. Figure 9 demonstrates the hydroxyl absorption of $\mathrm{EPh}$ in cyclohexane containing different concentrations of TAc. The intensity of the free hydroxyl absorption at 3620 $\mathrm{cm}^{-1}$ decreases with increasing TAc concentration. The absolute intensity of the free hydroxyl group at $3620 \mathrm{~cm}^{-1}$ is considered as a measurement of the amount of free hydroxyl in the mixture on the basis of eq 3. Therefore, the data on the level of $f_{\mathrm{m}}^{\mathrm{OH}}$ for $\mathrm{EPh}$ containing various concentrations of TAc can be calculated with the $K a$ values. The intrinsic interassociation constant $K a$ of (13.41 $\left.\mathrm{Lmol}^{-1}\right)$ is obtained by extrapolating TAc concentration to zero. $K a$ must be modified into $K_{\mathrm{A}}$ by dividing the molar volume of the phenolic repeated unit $\left(0.1 \mathrm{Lmol}^{-1}\right.$ at $\left.25^{\circ} \mathrm{C}\right) .{ }^{6}$ The interassociation equilibrium constant, $K_{\mathrm{A}}$, yielded through this procedure is 134.1.
The second method uses the numerical method to determine $K_{\mathrm{A}}$ according to PCAM on the basis of the fraction of hydrogen bonding of the carbonyl group. The approximate equations ${ }^{20}$ are

$$
\begin{aligned}
\Phi_{\mathrm{B}}=\Phi_{\mathrm{B} 1}\left\{\left(1-\frac{K_{2}}{K_{\mathrm{B}}}\right)+\frac{K_{2}}{K_{\mathrm{B}}}\left[\frac{1}{\left(1-K_{\mathrm{B}} \Phi_{\mathrm{B} 1)^{2}}\right.}\right]\right\} \\
\times\left(1+\frac{\mathrm{K}_{\mathrm{A}} \Phi_{0 \mathrm{~A}}}{r}\right) \\
\Phi_{\mathrm{A}}=\Phi_{0 \mathrm{~A}}+K_{\mathrm{A}} \Phi_{0 \mathrm{~A}} \Phi_{\mathrm{B} 1} \\
\times\left\{\left(1-\frac{\mathrm{K}_{2}}{\mathrm{~K}_{\mathrm{B}}}\right)+\frac{K_{2}}{K_{\mathrm{B}}}\left[\frac{1}{\left(1-K_{\mathrm{B}} \Phi_{\mathrm{B} 1}\right)}\right]\right\}
\end{aligned}
$$

where $\Phi_{\mathrm{A}}$ and $\Phi_{\mathrm{B}}$ denote volume fractions of nonself-associated species $\mathrm{A}$ and self associating species B, respectively; $\Phi_{0 \mathrm{~A}}$ and $\Phi_{\mathrm{B} 1}$ are the corresponding volume fractions of the isolated PAS and PVPh segments, respectively; $r$ is the ratio of molar volume, $V_{\mathrm{A}} / V_{\mathrm{B}}$; self-association equilibrium constants, $K_{\mathrm{B}}$ and $K_{2}$, describe the formation of multimers and dimers, respectively; and $K_{\mathrm{A}}$ is the equilibrium constant describing the association of A with B. In addition, $K_{\mathrm{B}}$ and $K_{2}$ are 66.8 and 21.0 at $25{ }^{\circ} \mathrm{C}$ of pure PVPh. ${ }^{6}$ To calculate the interassociation constants $\left(K_{\mathrm{A}}\right)$, the methodology of a least-squares method has been widely described in a previous study. ${ }^{20,21}$ The interassociation constant of 43.1 was obtained from the $\mathrm{PVPh} / \mathrm{PAS}$ $=50 / 50$ blend as a result of the highest fraction of hydrogen bonding at this composition.

Table 5 lists all the thermodynamic parameters in this polymer-blend system, indicating that the interassociation equilibrium constant from model compound is greater than the self-association equilibrium constant of pure $\mathrm{PVPh}$. However, the interassociation constant from the polymer blend is relatively smaller than that of the selfassociation, indicating that the $\mathrm{PVPh} / \mathrm{PAS}$ blend should be immiscible or partially miscible because of relatively poorer intermolecular association. In general, the interassociation constant of a polymer blend on the basis of model compounds has been described by Pehlert et al. ${ }^{14}$ as follows

$$
K_{\mathrm{A}}^{\mathrm{Std}}=K_{\mathrm{A}}^{\infty}-\left(\frac{C_{\mathrm{A}}}{R_{\mathrm{A}}^{0}+R_{\mathrm{A}}}+\frac{C_{\mathrm{B}}}{R_{\mathrm{B}}^{0}+R_{\mathrm{B}}}\right)
$$

where $R_{\mathrm{A}}^{0}$ and $R_{\mathrm{B}}^{0}$ denote the molar volumes of the respective homopolymers; $R_{\mathrm{A}}$ and $R_{\mathrm{B}}$ represent the average molar volume between the $\mathrm{A}$ and $\mathrm{B}$ 
Table 4. $f_{\mathrm{m}}^{\mathrm{OH}}$ and $\mathrm{Ka}$ of 4-Ethylphenol in Cyclohexane Solution with Various $p$-Tolyl Acetate Concentrations

\begin{tabular}{ccccc}
\hline $\begin{array}{c}\text { Concentration of } p \text {-Tolyl } \\
\text { Acetate (mol/L) }\end{array}$ & $\begin{array}{c}\text { Intensity of IR } \\
\text { Absorption }\end{array}$ & $f_{\mathrm{m}}^{\mathrm{Oh}}$ & $\begin{array}{c}K_{\mathrm{A}} \\
(\mathrm{mol} / \mathrm{L})\end{array}$ & $\begin{array}{c}\mathrm{KA}^{\text {Std }} \\
(\text { Dimensionless })\end{array}$ \\
\hline 0.08 & 0.0235 & 0.687 & 13.41 & \\
0.05 & 0.0225 & 0.657 & 12.04 & \\
0.1 & 0.0177 & 0.517 & 10.31 & \\
0.2 & 0.0118 & 0.345 & 10.15 & 134.1 \\
0.25 & 0.0104 & 0.304 & 9.69 & \\
0.4 & 0.0091 & 0.266 & 7.47 & \\
0.5 & 0.0074 & 0.216 & 7.15 & \\
\hline
\end{tabular}

groups, respectively; $C_{\mathrm{A}}$ and $C_{\mathrm{B}}$ are fitting constants; and $K_{\mathrm{A}}^{\infty}$ is considered as the intramolecular screening effect using an appropriate $r$ value for a polymer blend of $0.30 .{ }^{12}$ Therefore, the interassociation constant is given by

$$
K_{\mathrm{A}}^{\infty}=K_{\mathrm{A}}^{\text {model }}(1-\gamma)
$$

where $K_{\mathrm{A}}^{\circ}$ has a value of $134.1 \times 0.7=93.87$ (dimensionless units). Using $C_{\mathrm{A}}=1630$ and $C_{\mathrm{B}}$ $=4100$ previously reported by Pehlert et al. ${ }^{14}$ for blends of PVPh and poly(vinyl acetate) results in a similar structure between PAS and poly(vinyl acetate). Consequently, eq 6 can be expressed as a function of $R_{\mathrm{A}}$ and $R_{\mathrm{B}}$ for the PSOH/PAS blend as follows

$$
K_{\mathrm{A}}^{\mathrm{std}}=93.87-\left(\frac{1630}{128.6+R_{\mathrm{A}}}+\frac{4100}{100+R_{\mathrm{B}}}\right)
$$

Considering $R_{\mathrm{A}}=0$ and $R_{\mathrm{B}}=0$ indicate that $K_{\mathrm{A}}$ $=40.19$ for the PVPh/PAS blend system. This value is very close to the data from the numerical method in the polymer blend, indicating that the thermodynamics properties in a polymer blend can be predicted from analogous model compounds after considering the intramolecular screening and functional-group accessibility effects.

Therefore, the incorporation of an inert diluent moiety such as styrene or dimethylbutadiene ${ }^{14}$ into $\mathrm{PVPh}$ is able to increase the standard interassociation equilibrium constant as a result of the increase of the $R_{\mathrm{B}}$ value. However, the total numbers of hydrogen bonding significantly decrease, and the solubility parameter difference increases with increasing styrene content in the PSOH copolymers especially for those with a higher styrene content (87-100 mol \%). Therefore, an optimum vinylphenol content in the $\mathrm{PSOH}$ copolymer is expected to have the most-favorable trend to form a miscible blend because of the competition between these two opposing effects.

In general, the miscibility of an immsicible blend can be enhanced by introducing a suitable functional group to one component capable of

\begin{tabular}{|c|c|c|c|c|c|c|}
\hline & $\begin{array}{l}\text { Equilibrium } \\
\text { Constant } K \\
\left(25^{\circ} \mathrm{C}\right)\end{array}$ & Polymer & $\begin{array}{c}\text { Molar } \\
\text { Volume } \\
(\mathrm{mL} / \mathrm{mol})\end{array}$ & $\begin{array}{l}\text { Molecular } \\
\text { Weight } \\
\text { (g/mol) }\end{array}$ & $\begin{array}{l}\text { Solubility } \\
\text { Parameter } \\
(\mathrm{cal} / \mathrm{mL})^{0.5}\end{array}$ & $\begin{array}{c}\text { Degree of } \\
\text { Polymerization } \\
\text { (DP) }\end{array}$ \\
\hline $\begin{array}{l}\text { Self-association }^{\mathrm{a}} \\
\text { Dimer formation } K_{2} \\
\text { Multimer formation } K_{\mathrm{B}} \\
\text { Interassociation from } \\
\quad \text { model compound } \\
\text { Interassociation from } \\
\text { polymer blend }\end{array}$ & $\begin{array}{r}21.0 \\
66.8 \\
\\
134.1 \\
\\
43.1\end{array}$ & $\begin{array}{r}\mathrm{PVPh}^{\mathrm{b}} \\
\mathrm{PAS}^{\mathrm{b}} \\
\mathrm{PS}^{\mathrm{b}}\end{array}$ & $\begin{array}{r}100.0 \\
128.6 \\
93.9\end{array}$ & $\begin{array}{l}120.1 \\
162.2 \\
104.1\end{array}$ & $\begin{array}{r}10.6 \\
10.29 \\
9.48\end{array}$ & $\begin{array}{r}86 \\
132 \\
132\end{array}$ \\
\hline
\end{tabular}

Table 5. Summary of the Self-Association and Interassociation Parameters of PVPh/PAS Blend

${ }^{\text {a }}$ Reference ${ }^{6}$.

${ }^{\mathrm{b}}$ Estimated with a group contribution method proposed by Coleman et al. ${ }^{6}$ 
forming intermolecular association with other components. ${ }^{22}$ In our previous studies, ${ }^{23,24}$ we found that the phenolic group is miscible with PS-co-PAS copolymers when its acetoxystyrene content is higher than $45 \mathrm{~mol} \%$ in the phenolic/ PS-co-PAS blend system, whereas the vinylphenol content of $13 \%$ or higher in the PSOH is also required to make the $\mathrm{PSOH} / \mathrm{poly}$ ( $\varepsilon$-caprolactone) (PCL) blend miscible. However, in this study, the immisicible PVPh/PAS blend needs to incorporate the inert diluent moiety such as styrene into the PVPh component to obtain a miscible blend system because of a reduced stronger self-association of the PVPh component in the blend. In fact, this phenomenon can also be explained with the copolymer repulsion effect. ${ }^{25,26}$ The enthalpy of mixing is usually responsible for the miscibility because the contribution from the entropy changes for a polymer blend is usually insignificant. For a binary mixture of homopolymer A with a $C_{\mathrm{y}} D_{1-\mathrm{y}}$ copolymer, the expression for the enthalpy of mixing is given by eq 9

$$
\frac{\Delta H_{\mathrm{M}}}{V}=B \Phi_{1} \Phi_{2}
$$

where $V$ is the total volume of mixture, $\Phi_{1}$ and $\Phi_{2}$ are their respective volume fractions, and $y$ is the molar fraction of component $C$ in copolymer. The $B$ value in eq 9 can be expressed as

$$
B=y B_{\mathrm{AC}}+(1-y) B_{\mathrm{AD}}-y(1-y) B_{\mathrm{CD}}
$$

Interaction parameter $B$ has to be negative for a polymer blend to be miscible. Therefore, the miscibility of a blend containing a copolymer depends on the segmental $B_{\mathrm{CD}}$ values and the copolymer composition as shown in eq 10 . PVPh and PS are immiscible with each other. Therefore, the $B$ value in eq 10 tends to be negative, whereas $B_{\mathrm{CD}}$ is positive because of the immiscibility of PVPh and PS. The incorporation of styrene moiety into PVPh makes PVPh more favorable to interact with PAS than PS, and this phenomenon also enhances the miscibility between PVPh and PAS. This concept of the copolymer repulsion effect is consistent with the Painter-Coleman association model in this blend system.

\section{CONCLUSIONS}

Miscibility behaviors of blends of PAS with pure PVPh and a series of PSOH copolymers contain- ing various styrene contents have been investigated. Experimental results indicated that the $\mathrm{PVPh} / \mathrm{PAS}$ blend is an immiscible system based on two $T_{\mathrm{g}}$ 's. This immiscibility is caused by the stronger self-association of the $\mathrm{PVPh}$ component than the interassociation of the PVPh/PAS blend. However, the incorporation of styrene moiety into the PVPh main chain is able to enhance its miscibility with PAS because of the increase of the standard interassociation equilibrium constant between the hydroxyl group in PSOH copolymers and the carbonyl group in PAS. However, the incorporation of an excessively high PS content (87-100 mol \%) into the PVPh tends to increase the solubility parameter difference and decrease the total number or density of hydrogen bonding with PAS, and thus decreases its miscibility. Compromising these two opposing effects, the miscibility window between 16 and $50 \mathrm{~mol} \%$ vinylphenol content in the PSOH copolymer results in miscible blends with PAS. Furthermore, the interassociation equilibrium constant of $\mathrm{PVPh} /$ PAS blends determined by model compounds and a polymer blend exhibits good correlation between these two methods after considering the intramolecular screening and functional-group accessibility effects.

This research was financially supported by the $\mathrm{Na}$ tional Science Council (Taiwan, Republic of China) under contract number NSC-90-2216-E-009-026.

\section{REFERENCES AND NOTES}

1. Coleman, M. M.; Painter, P. C. Prog Polym Sci 1995, 20, 1.

2. Goh, S. H.; Lee, S. Y.; Luo, X.; Wong, M. W.; Tan, K. L. Macromol Chem Phys 2001, 202, 31.

3. Li, L.; Chan, C. M.; Weng, L. T.; Xiang, M. L. Macromolecules 1998, 31, 7428.

4. Kuo, S. W.; Chang, F. C. Macromolecules 2001, 34, 4089.

5. Hill, D. J. T.; Whittaker, A. K.; Wong. K. W. Macromolecules 1999, 32, 5285.

6. Coleman, M. M.; Graf, J. F.; Painter, P. C. Specific Interactions and the Miscibility of Polymer Blends; Technomic: Lancaster, PA, 1991.

7. Whestel, K. B.; Lady, J. H. Spectroscopy of Fuels; Plenum: London, 1970.

8. Coggesthall, N. D.; Saier, E. L. J Am Chem Soc 1951, 71, 5414.

9. Hu, Y.; Motzer, H. R.; Etxeberria A. M.; FernadezBerridi, M. J.; Iruin, J. J.; Painter, P. C.; Coleman, M. M. Macromol Chem Phys 2000, 201, 705. 
10. Kuo, S. W.; Chang, F. C. Macromolecules 2001, 34, 5224.

11. Kuo, S. W.; Chang, F. C. Macromol Chem Phys 2002, 203, 868.

12. Painter, P. C.; Veytsman, B.; Kumar, S.; Shenoy, S.; Graf, J. F.; Xu, Y.; Coleman, M. M. Macromolecules 1997, 30, 932.

13. Coleman, M. M.; Pehlert, G. J.; Painter, P. C. Macromolecules 1996, 29, 6820.

14. Pehlert, G. J.; Painter, P. C.; Veytsman, B.; Coleman, M. M. Macromolecules 1997, 30, 3671.

15. Pehlert, G. J.; Painter, P. C.; Coleman, M. M. Macromolecules 1998, 31, 8423.

16. Coleman, M. M.; Guigley, K. S.; Painter, P. C. Macromol Chem Phys 1999, 200, 1167.

17. Painter, P. C.; Coleman, M. M. Polymer Blends; Paul, D. R., Ed.; Wiley: New York, 2000; Vol. 1, p 93.
18. Moskala, E. J.; Varnell, D. F.; Coleman, M. M. Polymer 1985, 26, 228.

19. Hu, Y.; Painter, P. C.; Coleman, M. M. Macromol Chem Phys 2000, 201, 470.

20. Coleman, M. M.; Lichkus, A. M.; Painter, P. C. Macromolecules 1989, 22, 586.

21. Kuo, S. W.; Chang, F. C. Macromol Chem Phys 2001, 202, 3112.

22. Chien, Y. Y.; Perace, E. M.; Kwei, T. K. Macromolecules 1988, 21, 616.

23. Kuo, S. W.; Chang, F. C. Polymer 2001, 42, 9843.

24. Kuo, S. W.; Chang, F. C. Macromolecules 2001, 34, 7737.

25. Paul, D. R.; Barlow, J. W. Polymer 1984, 25, 4870.

26. Panayiotou, C. Makromol Chem 1987, 188, 2733. 